\title{
DRIFT POTENTIAL FROM GLYPHOSATE AND 2,4-D APPLICATIONS AS INFLUENCED BY NOZZLE TYPE, ADJUVANT, AND AIRSPEED
}

\author{
G. Sousa Alves, B. C. Vieira, T. R. Butts, \\ S. M. Silva, J. P. A. R. Da Cunha, G. R. Kruger
}

\begin{abstract}
HighLIGHTS
- The AIXR nozzle and modified vegetable oil reduce drift potential.

- Downwind spray deposition increases non-linearly as airspeed increases.

- Nozzle selection is more important than adjuvant to mitigate spray drift.
\end{abstract}

\begin{abstract}
Spray drift is a critical concern for pesticide applications and the largest focus for its reduction has been placed on increasing droplet size. The objectives of this research were to evaluate the influence of nozzle type, adjuvant, and airspeed on the droplet spectrum and spray drift deposits from applications of glyphosate plus 2,4-D in a wind tunnel. Two studies were conducted using three 11002 nozzles types (XR, DG, and AIXR) individually attached to a one-tip boom. The working pressure was $207 \mathrm{kPa}$. The first study evaluated drift from the potassium salt of glyphosate $(1260 \mathrm{~g}$ ae ha-1) plus 2,4-D amine (450 $\mathrm{g}$ ae ha-1) tank-mixed with four adjuvants (individually) sprayed at $2.2 \mathrm{~m} \mathrm{~s}^{-1}$ airspeed. A glyphosate plus 2,4-D solution with no tank-mixed adjuvants was also evaluated. The second study evaluated drift from glyphosate plus 2,4D applications in four airspeeds $\left(0.9,2.2,3.6\right.$, and $\left.4.9 \mathrm{~m} \mathrm{~s}^{-1}\right)$. Drift potential was determined using 2 mm monofilament line collectors and a 1,3,6,8-pyrenetetrasulfonic acid tetra sodium salt (PTSA) fluorescent tracer added to solutions, quantified by fluorometry. Nozzles and adjuvants influenced droplet size distribution of glyphosate plus 2,4-D solutions. Among the

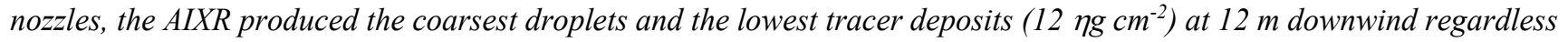
of solution type. When nozzles were pooled, the modified vegetable oil (MVO) reduced the spray deposition by $36 \%$ at $12 \mathrm{~m}$ compared to the solution without adjuvant. At $4.9 \mathrm{~m} \mathrm{~s}^{-1}$ airspeed, tracer deposit at $12 \mathrm{~m}$ downwind was 2-fold lower when applications were made through low-drift nozzles (DG and AIXR) compared to the XR nozzle. Results suggest that driftreducing adjuvants tested in this study may not reduce drift and nozzle selection should be considered as a more important factor than adjuvants in order to mitigate spray drift.
\end{abstract}

Keywords. Drift-reducing technology, Surfactants, Wind tunnel.

\footnotetext{
(c) (1) (8) $(\mathrm{)}$

The authors have paid for open access for this article. This work is licensed under a Creative Commons AttributionNonCommercial-NoDerivatives 4.0 International License https://creative commons.org/licenses/by-nc-nd/4.0/.

Submitted for review in July 2019 as manuscript number NRES 13604; approved for publication as a Research Article by the Natural Resources \& Environmental Systems of ASABE in May 2020.

The authors are Guilherme Sousa Alves, Research Associate, West Central Research and Extension Center, University of Nebraska-Lincoln, North Platte, Nebraska; Bruno C. Vieira, Research Associate, West Central Research and Extension Center, University of Nebraska-Lincoln, North Platte, Nebraska; Thomas R. Butts, Assistant Professor, Extension Weed Scientist, University of Arkansas System Division of Agriculture, Lonoke, Arkansas; Sérgio M. Silva, Professor, Federal University of 'Vales do Jequitinhonha e Mucurí', Unaí, Minas Gerais, Brazil; João Paulo A. R. da Cunha, Professor, Federal University of Uberlândia, Minas Gerais, Brazil; and Greg. R. Kruger, Associate Professor, West Central Research and Extension Center, University of Nebraska-Lincoln, North Platte, Nebraska. Corresponding author: Guilherme Sousa Alves, 402 West State Farm Road, North Platte, NE, 69101; phone: 308-696-6780; e-mail: guilherme.alves@unl.edu.
}

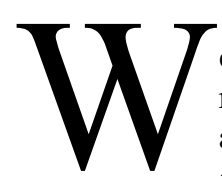

eed management is a primary concern for agricultural producers. Weeds have caused an average annual yield loss in North American corn (Zea mays L.) and soybean [Glycine $\max ($ L.) Merrill] crops of $50 \%$ and $52 \%$, respectively, equating to annual revenue losses of $\$ 26.7$ and $\$ 17.2$ billion dollars, respectively (Soltani et al., 2016, 2017). Herbicides are the most commonly-used weed management tool because they are cost-effective and provide timely weed control (Reddy, 2001). Over $91 \%$ of all corn, soybean, and cotton (Gossypium hirsutum L.) hectares received an herbicide application in 2016 and 2017 across the United States (USDA-NASS, 2017). In these applications, glyphosate and 2,4-D were among the top five most used active ingredients (Fernandez-Cornejo et al., 2014). In addition, broadleaf crops that are naturally sensitive to 2,4-D, such as soybeans, have been genetically modified to become tolerant to 2,4-D (Wright et al., 2010), which will increase its use in agriculture and may lead to damages on nearby sensitive crops due to off-target movement during the applications. 
Although applications of glyphosate and 2,4-D are prevalent, the pesticide application process is complex (Ebert et al., 1999), and a multitude of factors must be accounted for to optimize each application (Kudsk, 2017). A 2016 survey from Missouri identified that more than $62 \%$ of applicators changed nozzles less than $50 \%$ of the time when switching herbicide products, and on average, only $45 \%$ of applicators inspected sprayer parts prior to each application (Bish and Bradley, 2017). As a result, unsuitable or inefficient applications may occur due to improper nozzle selection and other undetected issues (Klein and Kruger, 2011), which potentially leads to increased spray drift.

Spray drift is a critical concern for herbicide applications as previous research determined severe crop injury could occur up to $200 \mathrm{~m}$ downwind when synthetic auxin herbicides, such as 2,4-D, were applied (Byass and Lake, 1977). Additionally, previous research reported that crop injury can occur on exposed susceptible crops due to downwind drift from applications of glyphosate, 2,4-D, and dicamba herbicides (Johnson et al., 2006; Egan et al., 2014; Alves et al., 2017a; Kalsing et al., 2018). Drift may also contribute to the evolution of herbicide resistance as sublethal doses have been found to hasten the evolution process (Neve and Powles, 2005; Vieira et al., 2020a).

Multiple application factors, including droplet velocity and trajectory, boom height, distance to susceptible vegetation, air temperature and relative humidity, and wind speed influence spray drift have been previously used in drift prediction models (Miller and Hadfield, 1989; Hobson et al., 1993; Zhu et al., 1994; Smith et al., 2000). The largest focus for spray drift reduction practices has been placed on increasing spray droplet size evidenced by new herbicide labels registered by the U.S. Environmental Protection Agency requiring specific nozzle types, operating pressures, and tank-mixture combinations to be evaluated for their droplet size distributions prior to approval (Anonymous, 2017a, 2017b). This is because spray droplet size is one of the most manageable factors influencing pesticide applications and drastic reductions in downwind spray drift are possible when droplet size is increased (Alves et al., 2017b; Bueno et al., 2017; Vieira et al., 2018). Spray droplet size has been shown to be impacted by numerous factors including: adjuvants, pesticide formulations, interactions between spray solution chemistry and nozzle, nozzle orifice size, and application pressure (Butler Ellis et al., 1997; Butler Ellis and Tuck, 2000; Miller and Butler Ellis, 2000; Nuyttens et al., 2007a; Creech et al., 2015). Nozzle design or type influenced the emitted droplet size in both aerial and ground applications (Bouse, 1994; Nuyttens et al., 2007a) and was identified as the variable with the greatest influence over droplet size (Creech et al., 2015). Therefore, further research is needed to identify application parameters, specifically commonly-used nozzles and adjuvants, that can effectively increase droplet size and reduce drift potential of an application.

Because weather conditions cannot be controlled, it is very difficult to perform spray drift measurements in the field with a high degree of repeatability (Miller and Butler Ellis, 2000). Previous research indicates that the wind tunnel drift simulation method in controlled conditions reproduced near-field spray drift conditions (Vieira et al., 2018, 2019), which makes the wind tunnel suited for studies where relative drift values are required (Derksen et al., 1999; Sidahmed et al., 2004).

The objectives of this research were: (1) to characterize the effects of nozzle type, adjuvant, and airspeed on downwind spray drift deposits from a tank-mixture of glyphosate (potassium salt) and 2,4-D amine in a low-speed wind tunnel; and (2) to identify the influence of nozzle type and adjuvant on the droplet size distribution from a tank-mixture of glyphosate plus 2,4-D amine.

\section{MATERIALS AND MeTHODS}

Experiments were conducted at the Pesticide Application Technology Laboratory (PAT Lab) at the West Central Research and Extension Center of the University of NebraskaLincoln in North Platte, Nebraska, in 2015. Treatments were performed in a low-speed wind tunnel with plexiglass walls and square working sections of $1.2 \mathrm{~m}$ wide, $1.2 \mathrm{~m}$ high, and $15 \mathrm{~m}$ long (Alves et al., 2017a). Applications were made at environmental conditions of $20^{\circ} \mathrm{C}\left( \pm 2^{\circ} \mathrm{C}\right)$ air temperature and $60 \%( \pm 5 \%)$ relative humidity. The wind tunnel facility has an air-conditioning system that controlled air temperature and relative humidity held stable throughout the testing period naturally. One study was conducted to measure the spray droplet size distribution of nozzle type and adjuvant combination treatments when tank-mixed with glyphosate and 2,4-D amine. Two additional, separate studies were conducted to evaluate the effects of nozzle type, adjuvant, and airspeed on downwind spray drift deposits from a tank-mixture application of glyphosate and 2,4-D amine.

\section{Droplet Size Measurements}

Droplet spectrum for each combination of five spray solutions ([herbicide solution (HS) alone and tank-mixed with either non-ionic surfactant (NIS), drift reduction agent (DRA), modified vegetable oil (MVO), or silicone surfactant (SIL)] and three flat-fan nozzle types [Extended Range (XR11002), Drift Guard (DG11002), and Air Induction Extended Range (AIXR11002) (Spraying Systems Co., Wheaton, Ill.)] was evaluated at $207 \mathrm{kPa}$. Herbicide solution was composed of the potassium salt of glyphosate (Roundup PowerMax ${ }^{\circledR}$, Monsanto Co., St Louis, Mo.) and 2,4-D amine (DMA 4 IVM $^{\mathrm{TM}}$, Dow AgroSciences LLC., Indianapolis, Ind.) at rates of 1260 and $450 \mathrm{~g}^{2} \mathrm{ha}^{-1}$, respectively. Four adjuvants (Wilbur-Ellis Co. LLC, Fresno, Calif.) were individually tank-mixed at maximum label rates with the glyphosate plus 2,4-D amine solution (table 1). An additional HS with no tank-mixed adjuvants was also tested. Solutions were prepared simulating an application at $94 \mathrm{~L} \mathrm{ha}^{-1}$.

Droplet spectrum was analyzed using a Sympatec HELOS-VARIO K/R laser diffraction droplet sizing system (Sympatec Inc., Clausthal, Germany) set up with an R7 lens with a dynamic size range of 18 to $3500 \mu \mathrm{m}$ across 31 sizing bins. The distance from the nozzle tip to the laser was $0.3 \mathrm{~m}$. This system is integrated into the wind tunnel and the airspeed was maintained at $6.7 \mathrm{~m} \mathrm{~s}^{-1}$ during data acquisition (Fritz et al., 2014a; Butts et al., 2019a). Three replicated 
Table 1. Adjuvants tank-mixed with glyphosate plus 2,4-D amine solutions.

\begin{tabular}{|c|c|c|c|}
\hline Abbreviation $^{[\mathrm{a}]}$ & Adjuvant Ingredient & Trade Name ${ }^{[\mathrm{b}]}$ & Rate \\
\hline & & & $\% \mathrm{~V} \mathrm{v}^{-1}$ \\
\hline NIS & alkylphenol ethoxilate, butyl alcohol, dimethylpolysiloxane & $\mathrm{R}-11^{\circledR}$ & 0.37 \\
\hline DRA & modified vegetable oil, amine salts of organic acids, organic acids & Crosshair $^{\circledR}$ & 0.31 \\
\hline MVO & methyl soyate, nonylphenol ethoxilate blend & Superspread $^{\mathrm{TM}} \mathrm{MSO}$ & 2.00 \\
\hline SIL & polyether, polymethylsiloxane, copolymer and polyether & Syl-Coat ${ }^{\mathrm{TM}}$ & 0.37 \\
\hline
\end{tabular}

[a] NIS, non-ionic surfactant; DRA, drift reduction agent; MVO, modified vegetable oil; SIL, silicone surfactant.

[b] Wilbur-Ellis Co. LLC, Fresno, Calif..

measurements were collected for each treatment. Spray parameters of interest were $\mathrm{D}_{\mathrm{v} 0.1}, \mathrm{D}_{\mathrm{v} 0.5}$, and $\mathrm{D}_{\mathrm{v} 0.9}$ (the droplet diameters for which $10 \%, 50 \%$, and $90 \%$ of the total spray volume is contained in droplets of lesser diameter, respectively), relative span (RS), and volume percentage of droplets smaller than $100 \mu \mathrm{m}$ (percent fines - $\left.\mathrm{V}_{100}\right)(A S A B E$ Standards, 2016). Relative span is a dimensionless parameter that indicates uniformity of droplet size distribution, calculated using equation 1 , while $\mathrm{V}_{100}$ is an indicator of the potential risk of drift.

$$
R S=\frac{(D \nu 0.9-D v 0.1)}{D v 0.5}
$$

where

$\mathrm{RS}=$ relative span (dimensionless)

$\mathrm{D}_{\mathrm{v} 0.9}=$ volumetric diameter of droplets in which $90 \%$ of the total spray volume is contained in droplets of lesser diameter $(\mu \mathrm{m})$

$\mathrm{D}_{\mathrm{v} 0.5}=$ volumetric diameter of droplets in which $50 \%$ of the total spray volume is contained in droplets of lesser diameter $(\mu \mathrm{m})$

$\mathrm{D}_{\mathrm{v} 0.1}=$ volumetric diameter of droplets in which $10 \%$ of the total spray volume is contained in droplets of lesser diameter $(\mu \mathrm{m})$.

Spray classifications were determined using the ASABE S572.1 standard (ASABE Standards, 2017) modified to adjust for real-world scenarios as it has been widely accepted that pesticide formulation affects droplet size (Miller and Butler Ellis, 2000; Creech et al., 2015). Reference nozzles were used to apply water alone and generate spray classification reference curves in accordance with S572.1 standard.
The droplet size from tested herbicide solution and research nozzle pairings was then evaluated and a spray classification generated to account for both the herbicide solution and nozzle effect on droplet size. These methods are common to adjust for differences among laboratory settings (Fritz et al., 2014b) and evaluate a multitude of herbicide formulation by nozzle interactions affecting spray classifications (Henry et al., 2016; Creech et al., 2018; Vieira et al., 2018; Butts et al., 2018, 2019b).

\section{DOWNWIND SPRAY DEPOSITION Adjuvant and Nozzle Type Study}

A study to evaluate the interaction between adjuvant and nozzle type on downwind spray deposition in a low-speed wind tunnel was conducted in a completely randomized design with five replications in a $5 \times 3 \times 7$ split-split-plot arrangement with spatial units. Main plots consisted of the five spray solutions aforementioned (HS alone and tank-mixed with either NIS, DRA, MVO, or SIL). Subplots consisted of three flat-fan nozzle types (XR11002, DG11002, and AIXR11002). Sub-subplots consisted of seven downwind distances from the nozzle $(2,3,4,5,6,7$, and $12 \mathrm{~m})$. A diagram shows the experimental design for the first replicate (fig. 1). These nozzles were chosen because many burndown applications using older glyphosate plus 2,4-D formulations (2,4-D amine) are still made with DG and AIXR nozzles. The XR nozzle was used to represent the worst-case scenario.

The herbicides, adjuvants, and their respective rates were the same used in the Droplet Size Measurements Study. Solutions were prepared simulating an application at $94 \mathrm{~L} \mathrm{ha}^{-1}$. In addition, a 1,3,6,8-pyrenetetrasulfonic acid tetra sodium

Replicate 1

\begin{tabular}{|c|c|c|c|c|c|c|c|c|c|c|c|c|c|c|c|c|c|c|c|c|c|}
\hline \multirow{3}{*}{$\begin{array}{l}\text { Main plot (solution) } \\
\text { Subplot (nozzle) } \\
\text { Sub-subplot (distance) }\end{array}$} & \multicolumn{21}{|c|}{ HS } \\
\hline & \multicolumn{7}{|c|}{ XR 11002} & \multicolumn{7}{|c|}{ AIXR 11002} & \multicolumn{7}{|c|}{ DG 11002} \\
\hline & 2 & 3 & 4 & 5 & 6 & 7 & 12 & 2 & 3 & 4 & 5 & 6 & 7 & 12 & 2 & 3 & 4 & 5 & 6 & 7 & 12 \\
\hline Main plot (solution) & \multicolumn{21}{|c|}{ HS + DRA } \\
\hline Subplot (nozzle) & \multicolumn{7}{|c|}{ XR 11002} & \multicolumn{7}{|c|}{ DG 11002} & \multicolumn{7}{|c|}{ AIXR 11002} \\
\hline Sub-subplot (distance) & 2 & 3 & 4 & 5 & 6 & 7 & 12 & 2 & 3 & 4 & 5 & 6 & 7 & 12 & 2 & 3 & 4 & 5 & 6 & 7 & 12 \\
\hline Main plot (solution) & \multicolumn{21}{|c|}{$\mathrm{HS}+\mathrm{NIS}$} \\
\hline Subplot (nozzle) & \multicolumn{7}{|c|}{ DG 11002} & \multicolumn{7}{|c|}{ XR 11002} & \multicolumn{7}{|c|}{ AIXR 11002} \\
\hline Sub-subplot (distance) & 2 & 3 & 4 & 5 & 6 & 7 & 12 & 2 & 3 & 4 & 5 & 6 & 7 & 12 & 2 & 3 & 4 & 5 & 6 & 7 & 12 \\
\hline Main plot (solution) & \multicolumn{21}{|c|}{$\mathrm{HS}+\mathrm{SIL}$} \\
\hline Subplot (nozzle) & \multicolumn{7}{|c|}{ AIXR 11002} & \multicolumn{7}{|c|}{ DG 11002} & \multicolumn{7}{|c|}{ XR 11002} \\
\hline Sub-subplot (distance) & 2 & 3 & 4 & 5 & 6 & 7 & 12 & 2 & 3 & 4 & 5 & 6 & 7 & 12 & 2 & 3 & 4 & 5 & 6 & 7 & 12 \\
\hline Main plot (solution) & \multicolumn{21}{|c|}{$\mathrm{HS}+\mathrm{MVO}$} \\
\hline Subplot (nozzle) & \multicolumn{7}{|c|}{ AIXR 11002} & \multicolumn{7}{|c|}{ XR 11002} & \multicolumn{7}{|c|}{ DG 11002} \\
\hline Sub-subplot (distance) & 2 & 3 & 4 & 5 & 6 & 7 & 12 & 2 & 3 & 4 & 5 & 6 & 7 & 12 & 2 & 3 & 4 & 5 & 6 & 7 & 12 \\
\hline
\end{tabular}

Figure 1. Diagram of the experimental design. Abbreviations: HS, herbicide solution; NIS, non-ionic surfactant; DRA, drift reduction agent; MVO, modified vegetable oil; and SIL, silicone surfactant. 
salt (PTSA) fluorescent tracer (Spectra Colors Corp., Kearny, N.J.) was added to the solutions at $600 \mathrm{mg} \mathrm{L}^{-1}$ to be detected by fluorometry (Fritz et al., 2011; Hoffmann et al., 2014; Roten et al., 2014).

All applications were performed at $207 \mathrm{kPa}$ pressure and in a $2.2 \mathrm{~m} \mathrm{~s}^{-1}$ airspeed at the nozzle height measured using a portable anemometer (Nielsen-Kellerman Inc., Kestrel ${ }^{\circledR}$ 4000, Boothwyn, $\mathrm{Pa}$.).

\section{Airspeed and Nozzle Type Study}

A study to evaluate the interaction between airspeed and nozzle type on downwind spray deposition in a low-speed wind tunnel was conducted in a completely randomized design with five replications in a $3 \times 4$ factorial scheme comprising the same three nozzle types described in the previous studies (XR, DG, and AIXR) and four airspeeds (0.9, 2.2, 3.6 , and $4.9 \mathrm{~m} \mathrm{~s}^{-1}$ ). The herbicide solution (tank-mixture of glyphosate and 2,4-D amine) and pressure $(207 \mathrm{kPa})$ were the same as used in the previous studies. Spray drift deposition was collected only at $12 \mathrm{~m}$ downwind from the nozzle, which is the furthest distance from the nozzle capable in the wind tunnel.

\section{Application and Wind Tunnel Set $U p$}

Prior to each application, collectors composed of colorless polymer monofilament line $2 \mathrm{~mm}$ in diameter of round shape (Oregon Products, Magnum Gatorline ${ }^{\mathrm{TM}}$, Portland, Ore.) and $1.0 \mathrm{~m}$ length were positioned at each distance, parallel to the tunnel floor and perpendicular to the air flow (fig. 2a). Applications were made using a one-nozzle spray boom. The flat fan tip discharge was oriented towards the tunnel floor and perpendicular to the air flow (fig. 2b). Nozzles and collectors were placed at 0.6 and $0.1 \mathrm{~m}$ above the tunnel floor, respectively (figs. 2c, 2d). A $1.2 \times 0.5 \mathrm{~m} \mathrm{rug}$ with polyethylene blades $1 \mathrm{~cm}$ tall (GrassWorx LLC., St. Louis, Mo.) was positioned on the sprayed area to absorb droplets. Each replication consisted of a continuous 10-s application $( \pm 0.2 \mathrm{~s})$, controlled by a digital auto shut-off timer switch (Intermatic Inc., EI 400C, Spring Grove, Ill.).

Once each application was performed, monofilament lines were collected and placed individually into pre-labeled plastic bags. In the laboratory, $40 \mathrm{~mL}$ of a $10 \% \mathrm{v} \mathrm{v}^{-1}$ isopropyl alcohol solution was added to each plastic bag using a bottle top dispenser (LabSciences Inc., 60000-BTR, Reno, $\mathrm{Nev}$.). Samples were then swirled and shaken to release fluorescent material. After the tracer was suspended in the solution, a $1.5 \mathrm{~mL}$ aliquot from each sample bag was drawn to fill a glass cuvette, which was placed in a PTSA module inside a fluorimeter (Turner Designs, Trilogy 7200.000, Sunnyvale, Calif.) using ultra-violet light to obtain fluorescent data. Tracer recovery from the collector was $96 \%$ and detection limit was $4 \eta \mathrm{g} \mathrm{mL}^{-1}$. Relative fluorescence units (RFU) data was converted into $\eta g$ of PTSA $\mathrm{cm}^{-2}$ of collector using the calibration curve of the tracer. The total circumferential area of outside surface of collector was used as sampling area.

\section{Statistical ANALYSES}

Droplet size data were subjected to analysis of variance (ANOVA) using Sisvar Statistical Software, version 5.6 (Ferreira, 2011). Comparisons were made using Scott Knott's multiple comparison test at $\alpha=0.05$. For analysis of deposition in both studies, Kolmogorov-Smirnov and Levene's tests were applied to analyze normality of residuals
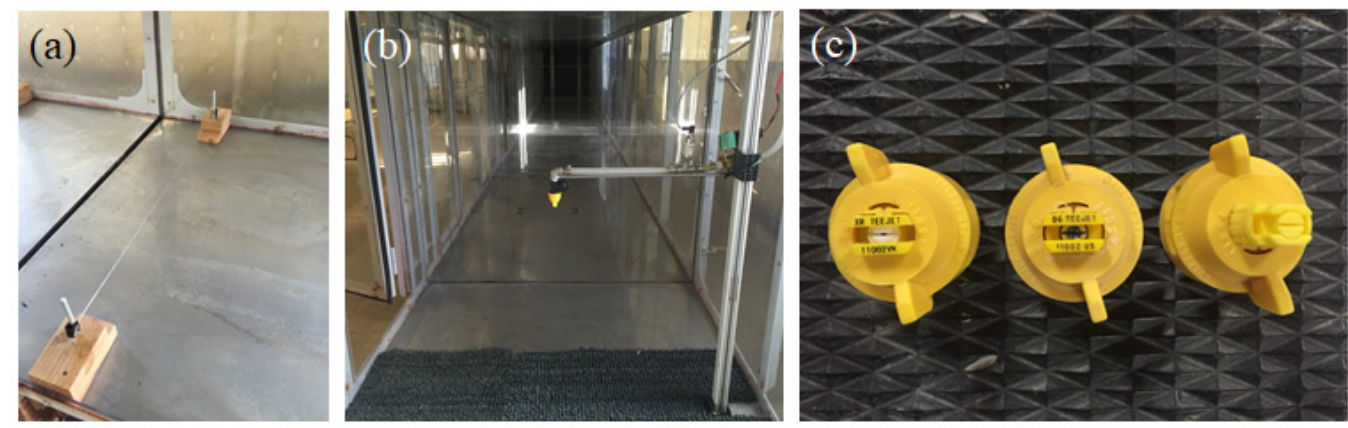

(d)

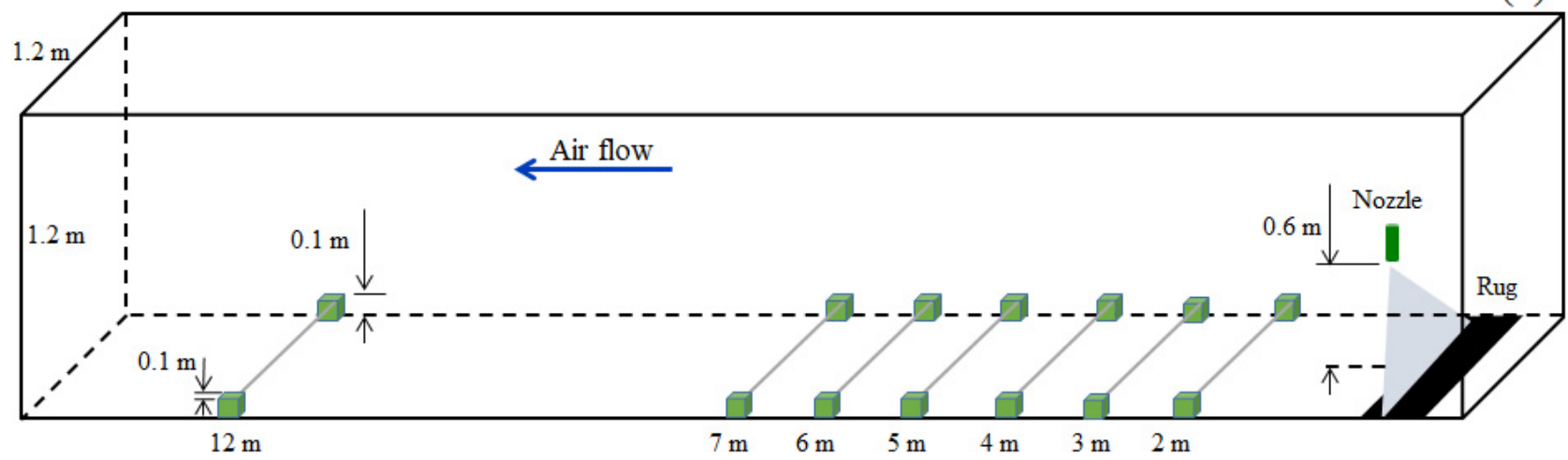

Figure 2. Drift collector (a), spray boom (b), nozzle types (c), and schematic drawing of the wind tunnel detailing the position of collectors and nozzle (d). Collectors placed from 2 to $12 \mathrm{~m}$ were used in the Adjuvant and Nozzle Type Study and only at $12 \mathrm{~m}$ were used in the Airspeed and Nozzle Type Study. 
and homogeneity of variance, respectively, using SPSS Statistical Software, version 20 (SPSS Inc., Chicago, Ill.). Deposition data were transformed by square root $(\mathrm{x})$ and then subjected to ANOVA at $\alpha=0.05$. Back-transformed data are presented for clarity. When significant differences were observed between nozzle type and adjuvant, nozzles and adjuvants were compared to each other by Tukey's multiple comparison test, whereas regression analysis was performed for the distances and airspeeds, both at $\alpha=0.05$. Regression models were made using SigmaPlot Software, version 14 (Systat Software Inc., Chicago, Ill.).

\section{RESULTS AND DISCUSSION \\ Droplet Size MEASUREMENTS}

The addition of SIL in HS reduced the droplet diameter $\left(D_{v 0.1}, D_{v 0.5}\right.$, and $\left.D_{v 0.9}\right)$ up to $20 \mu \mathrm{m}$, increased the $V_{100}$, and produced a more heterogeneous spectrum (greater RS) for all three nozzles compared to HS alone (table 2). The greatest potential risk of drift (largest $V_{100}$ and smallest $D_{v 0.1}$ ) for each nozzle type was produced using the SIL adjuvant compared to the other adjuvants and HS alone with $16.4 \%, 5.0 \%$, and $2.5 \%$ for the XR, DG, and AIXR nozzles, respectively. The adjuvant NIS produced similar droplet spectrum compared to HS alone for the XR and DG nozzles. However, it reduced the $D_{\mathrm{v} 0.5}$ and increased the percent fines for the AIXR nozzle in comparison to HS alone, HS plus DRA, and HS plus MVO. The adjuvant DRA did not affect the $D_{v 0.1}$ and $\mathrm{V}_{100}$ compared to the HS alone across nozzles; however, it increased the $\mathrm{D}_{\mathrm{v} 0.5}$ for the DG nozzle, did not alter the $\mathrm{D}_{\mathrm{v} 0.5}$ and decreased the $\mathrm{D}_{\mathrm{v} 0.9}$ for the AIXR nozzle. The adjuvant MVO increased the $D_{\mathrm{v} 0.5}$ of droplets compared to the other adjuvants and HS alone across nozzles. The HS plus MVO sprayed using the AIXR nozzle produced the lowest $\mathrm{V}_{100}$
$(0.50 \%)$. For XR and DG nozzles, MVO also reduced the $\mathrm{V}_{100}$ compared to the HS alone. The XR nozzle produced the finest droplets, followed by the DG and AIXR nozzles, respectively. These results suggest, regardless of nozzle type, that the use of MVO would be recommended for increasing the droplet size and reducing the percent fines, thereby reducing the drift potential of the application. However, to further reduce the drift potential of glyphosate plus 2,4-D amine, it is advisable to use a combination of an AIXR nozzle (coarse spray classification) and an MVO adjuvant. The adjuvants did not change the spray classification of the droplets according to ASABE S572.1 (ASABE Standards, 2017). According to the nozzle manufacturer, the XR11002, DG11002, and AIXR11002 nozzles produce Fine, Medium, and Very Coarse spray classification, respectively, using water at $207 \mathrm{kPa}$ pressure and $25^{\circ} \mathrm{C}$ temperature. Thus, the herbicides and adjuvants changed the spray classification from Very Coarse to Coarse in comparison to water alone when sprayed through AIXR nozzle.

These outcomes corroborate results that also discouraged the use of XR nozzles in high-wind environmental conditions due to increased drift potential (Johnson et al., 2006). Mota and Antuniassi (2013) also observed that solutions with vegetable and mineral oils provided coarser droplets compared to those produced using silicone adjuvants when sprayed through an air inclusion nozzle (Hypro ${ }^{\circledR}$ Guardian Air 11003). Opposite to results observed in this study, previous research showed the droplet volume diameter was increased by using drift-control adjuvants (polymer- and fatty acid-based) sprayed using an air inclusion nozzle (Teejet ${ }^{\circledR}$ AI11004) (Mota and Antuniassi, 2013). This highlights the importance of research such as this to evaluate the interaction between nozzle types and adjuvants on droplet size distribution and drift potential as conflicting results have been observed.

Table 2. Droplet spectrum from glyphosate plus 2,4-D amine solution tank-mixed with adjuvants sprayed through three nozzle types. ${ }^{[a]}$

\begin{tabular}{|c|c|c|c|c|c|c|}
\hline \multirow[b]{2}{*}{ Solution $^{[b]}$} & $\mathrm{D}_{\mathrm{v} 0.1}{ }^{[\mathrm{c}]}$ & $\mathrm{D}_{\mathrm{v} 0.5}$ & $\mathrm{D}_{\mathrm{v} 0.9}$ & $\mathrm{~V}_{100}$ & $\mathrm{RS}$ & \multirow[b]{2}{*}{ Spray Classification $^{\text {[d }}$} \\
\hline & \multicolumn{5}{|c|}{ XR 11002} & \\
\hline & --- & $---\mu \mathrm{m}-$ & ---- & $\%$ & & \\
\hline HS & $85 \mathrm{~h}$ & $192 \mathrm{j}$ & $339 \mathrm{f}$ & $14.91 \mathrm{j}$ & $1.32 \mathrm{i}$ & Fine \\
\hline $\mathrm{HS}+\mathrm{NIS}$ & $85 \mathrm{~h}$ & $193 j$ & $341 \mathrm{f}$ & $14.84 \mathrm{j}$ & $1.33 \mathrm{i}$ & Fine \\
\hline HS + DRA & $85 \mathrm{~h}$ & $194 \mathrm{j}$ & $342 \mathrm{f}$ & $14.67 \mathrm{j}$ & $1.32 \mathrm{i}$ & Fine \\
\hline $\mathrm{HS}+\mathrm{MVO}$ & $116 \mathrm{~g}$ & $220 \mathrm{i}$ & $344 \mathrm{f}$ & $6.12 \mathrm{i}$ & $1.03 \mathrm{c}$ & Fine \\
\hline $\mathrm{HS}+\mathrm{SIL}$ & $80 \mathrm{i}^{\circ}$ & $186 \mathrm{k}$ & $334 \mathrm{f}$ & $16.39 \mathrm{k}$ & $1.36 \mathrm{j}$ & Fine \\
\hline
\end{tabular}

\begin{tabular}{|c|c|c|c|c|c|c|c|}
\hline \multicolumn{8}{|c|}{ DG 11002} \\
\hline & & & $---\mu \mathrm{m}--$ & --- & $\%$ & & \\
\hline & HS & $136 \mathrm{e}$ & $295 \mathrm{~g}$ & $488 \mathrm{~d}$ & $4.26 \mathrm{~g}$ & $1.19 \mathrm{~g}$ & Medium \\
\hline & $\mathrm{HS}+\mathrm{NIS}$ & $137 \mathrm{e}$ & $296 \mathrm{~g}$ & $489 \mathrm{~d}$ & $3.92 \mathrm{f}$ & $1.19 \mathrm{~g}$ & Medium \\
\hline & HS + DRA & $137 \mathrm{e}$ & $300 \mathrm{f}$ & $495 \mathrm{~d}$ & $4.12 \mathrm{~g}$ & $1.19 \mathrm{~g}$ & Medium \\
\hline & $\mathrm{HS}+\mathrm{MVO}$ & $166 \mathrm{~d}$ & $321 \mathrm{e}$ & $487 \mathrm{~d}$ & $1.66 \mathrm{~b}$ & $0.99 \mathrm{~b}$ & Medium \\
\hline & $\mathrm{HS}+\mathrm{SIL}$ & $129 \mathrm{f}$ & $285 \mathrm{~h}$ & $479 \mathrm{e}$ & $5.03 \mathrm{~h}$ & $1.23 \mathrm{~h}$ & Medium \\
\hline \multicolumn{8}{|c|}{ AIXR 11002} \\
\hline & & & $--\mu \mathrm{m}-$ & ----- & $\%$ & & \\
\hline & HS & $178 \mathrm{~b}$ & $386 \mathrm{~b}$ & $604 \mathrm{a}$ & $2.01 \mathrm{c}$ & $1.10 \mathrm{e}$ & Coarse \\
\hline & HS + NIS & $174 \mathrm{c}$ & $382 \mathrm{c}$ & $595 \mathrm{~b}$ & $2.25 \mathrm{~d}$ & $1.10 \mathrm{e}$ & Coarse \\
\hline & HS + DRA & $179 \mathrm{~b}$ & $385 \mathrm{~b}$ & $594 \mathrm{~b}$ & $1.99 \mathrm{c}$ & $1.08 \mathrm{~d}$ & Coarse \\
\hline & $\mathrm{HS}+\mathrm{MVO}$ & $215 \mathrm{a}$ & $404 \mathrm{a}$ & $590 \mathrm{~b}$ & $0.50 \mathrm{a}$ & $0.93 \mathrm{a}$ & Coarse \\
\hline & HS + SIL & $168 \mathrm{~d}$ & $369 \mathrm{~d}$ & $584 \mathrm{c}$ & $2.48 \mathrm{e}$ & $1.12 \mathrm{f}$ & Coarse \\
\hline \multicolumn{8}{|c|}{ Averages followed by the same letter in the column do not differ using Scott Knott's test at $\alpha=0.05$. } \\
\hline [b] & \multicolumn{7}{|c|}{ Abbreviations: HS, herbicide solution; NIS, non-ionic surfactant; DRA, drift reduction agent; MVO, modified vegetable oil; SIL, silicone surfactant. } \\
\hline \multicolumn{8}{|c|}{ [c] $\mathrm{D}_{\mathrm{v} 0.1}, \mathrm{D}_{\mathrm{v} 0.5}, \mathrm{D}_{\mathrm{v} 0.9}$ : droplet diameter for which $10 \%, 50 \%$, and $90 \%$ of the total spray volume is contained in droplets of equal or lesser size, respectively; } \\
\hline \multicolumn{8}{|c|}{ Droplet spray classification according to ASABE S572.1 (ASABE Standards, 2017), obtained with each solution. } \\
\hline
\end{tabular}




\section{AdJuvant And Nozzle TyPe DRIFT STUdy}

A three-way interaction between solution, nozzle and distance was not significant at $\alpha=0.05$ for deposition data. Therefore, results were based on the interactions of solution versus nozzle $(p<0.0171)$, solution versus distance $(p<$ $0.0001)$, and nozzle versus distance $(p<0.0001)$. The MVO adjuvant tank-mixed with glyphosate plus 2,4-D amine solution reduced the spray deposition compared to the other adjuvants and $\mathrm{HS}$ alone for all three nozzles corroborating the droplet size distribution results (table 3). Conversely, NIS adjuvant increased the drift when compared with HS alone for all three nozzles. The AIXR nozzle generated the lowest spray deposition across solutions, from 105 to $172 \eta \mathrm{g} \mathrm{cm}^{-2}$, whereas the highest values were produced through the XR nozzle, from 292 to $429 \mathrm{\eta g} \mathrm{cm}^{-2}$. These results can be associated to the droplet size data, in which the MVO adjuvant and air inclusion nozzle produced coarser droplets and lower percent fines compared to the other solutions and nozzles.

The HS plus MVO produced the lowest spray deposition across distances when nozzles were pooled (table 4). Compared to HS alone, it reduced the deposition by $18 \%$ at $2 \mathrm{~m}$ and $36 \%$ at $12 \mathrm{~m}$. At the furthest distance from the nozzle (12 $\mathrm{m})$, HS plus NIS generated greater deposition compared to the HS alone. Although the SIL reduced the $D_{\mathrm{v} 0.5}$ of the droplet spectrum, the HS with this adjuvant produced similar spray deposition at $12 \mathrm{~m}$ compared with HS alone. Complementing these results, spray deposition decreased as downwind distance from nozzle increased following four-parameter exponential functions with R-squared values over 99\% (fig. 3).

As results presented in this study suggest, finer droplets and higher $\mathrm{V}_{100}$ (obtained using SIL) did not lead to a greater spray deposition at $12 \mathrm{~m}$ when compared to HS alone and pooled across nozzle types. By pooling the droplet size data across nozzle types, the $\mathrm{D}_{\mathrm{v} 0.1}$ and $\mathrm{V}_{100}$ of the HS plus SIL solution were $125 \mu \mathrm{m}$ and $7.97 \%$, respectively, whereas for the HS alone they were $133 \mu \mathrm{m}$ and $7.06 \%$, respectively. The differences of $8 \mu \mathrm{m}$ for $\mathrm{D}_{\mathrm{v} 0.1}$ and 0.91 percentage point for $\mathrm{V}_{100}$ between these two solutions were not great enough to produce difference on spray deposition at $12 \mathrm{~m}$ downwind. Each group of adjuvants has unique characteristics indicating that their use should depend on the specific purpose of each application (Oliveira et al., 2013). Although spray drift can be estimated based on droplet size distribution (Wang and Rautmann, 2009; EPA, 2017), a more appropriate recommendation regarding spray drift should be based on actual
Table 4. Tracer deposition from glyphosate plus 2,4-D amine applications tank-mixed with adjuvants. ${ }^{\text {[a] }}$

\begin{tabular}{cccccc}
\hline & \multicolumn{5}{c}{ Solution $^{[\mathrm{b}]}$} \\
\cline { 2 - 6 } $\begin{array}{c}\text { Distance } \\
(\mathrm{m})\end{array}$ & HS & HS + NIS & HS + DRA & HS + MVO & HS + SIL \\
\hline \multicolumn{5}{c}{ Ho co } \\
2 & $631 \mathrm{~b}$ & $802 \mathrm{~d}$ & $671 \mathrm{~b}$ & $514 \mathrm{a}$ & $727 \mathrm{c}$ \\
3 & $396 \mathrm{~b}$ & $448 \mathrm{~d}$ & $396 \mathrm{~b}$ & $307 \mathrm{a}$ & $426 \mathrm{bc}$ \\
4 & $259 \mathrm{~b}$ & $260 \mathrm{~b}$ & $254 \mathrm{~b}$ & $197 \mathrm{a}$ & $276 \mathrm{~b}$ \\
5 & $159 \mathrm{~b}$ & $195 \mathrm{c}$ & $177 \mathrm{bc}$ & $121 \mathrm{a}$ & $185 \mathrm{bc}$ \\
6 & $116 \mathrm{~b}$ & $135 \mathrm{c}$ & $125 \mathrm{bc}$ & $87 \mathrm{a}$ & $127 \mathrm{bc}$ \\
7 & $81 \mathrm{~b}$ & $98 \mathrm{c}$ & $97 \mathrm{bc}$ & $63 \mathrm{a}$ & $96 \mathrm{bc}$ \\
12 & $25 \mathrm{~b}$ & $35 \mathrm{c}$ & $34 \mathrm{bc}$ & $16 \mathrm{a}$ & $26 \mathrm{~b}$ \\
\hline
\end{tabular}

a] Averages followed by the same letter in the row do not differ using Tukey's test at $\alpha=0.05$. Data combined across nozzle types.

[b] HS, herbicide solution; NIS, non-ionic surfactant; DRA, drift reduction agent; MVO, modified vegetable oil; SIL, silicone surfactant.

drift measurements from fields, test benches or wind tunnel studies, especially for ground applications.

The XR nozzle produced the highest spray deposition across distances when solutions were pooled, ranging from $957 \mathrm{\eta g} \mathrm{cm}^{-2}$ at $2 \mathrm{~m}$ to $52 \eta \mathrm{g} \mathrm{cm}^{-2}$ at $12 \mathrm{~m}$ (fig. 4). Conversely, the AIXR nozzle produced the lowest spray deposition, ranging from $428 \mathrm{ng} \mathrm{cm}^{-2}$ at $2 \mathrm{~m}$ to $12 \mathrm{ng} \mathrm{cm}^{-2}$ at $12 \mathrm{~m}$ as can be seen by Tukey's mean separation. At $12 \mathrm{~m}$, the DG nozzle increased the spray deposition in $5 \mathrm{ng} \mathrm{cm}^{-2}$ in comparison to the AIXR nozzle. This can be explained as the AIXR nozzle produced the coarsest droplets $\left(\mathrm{D}_{\mathrm{v} 0.5}=\right.$ $367 \mu \mathrm{m})$, lowest $\mathrm{V}_{100}(2 \%)$, and had a more homogeneous droplet size spectrum (lower RS). For all three nozzles, deposition decreased exponentially as the distance increased. A study conducted on a test bench showed that non-air inclusion nozzles had greater drift potential than air inclusion nozzles (Gil et al., 2014). Furthermore, nozzle type and size, pressure, and boom height affect drift, and air inclusion nozzles had the greatest reduction of drift potential, followed by pre-orifice nozzles and standard flat-fan nozzles, respectively, similar to results observed in the present research (Nuyttens et al., 2007b).

\section{AIRSPEed ANd Nozzle TyPe DRIfT STUdy}

Downwind spray deposition was affected by a significant airspeed and nozzle type interaction $(p<0.0001)$. Deposition at $12 \mathrm{~m}$ downwind from the XR nozzle was greater than deposition generated from the DG and AIXR nozzles across airspeeds (fig. 5). The DG and AIXR nozzles generated similar deposit measurements at 0.9 and $4.9 \mathrm{~m} \mathrm{~s}^{-1}$, respectively, although the AIXR produced on average a $D_{\mathrm{v} 0.5} 80 \mu \mathrm{m}$

Table 3. Tracer deposition from glyphosate plus 2,4-D amine applications tank-mixed with adjuvants sprayed through three nozzle types. ${ }^{[a] ~[b]}$

\begin{tabular}{|c|c|c|c|c|c|c|}
\hline & & & & Solution $^{[\mathrm{c}]}$ & & \\
\hline & Nozzle & HS & $\mathrm{HS}+\mathrm{NIS}$ & $\mathrm{HS}+\mathrm{DRA}$ & $\mathrm{HS}+\mathrm{MVO}$ & $\mathrm{HS}+\mathrm{SIL}$ \\
\hline & & & --------------. & -ng cm-2- & - & \\
\hline & XR 11002 & $363 \mathrm{bC}$ & $429 \mathrm{cC}$ & $405 \mathrm{bcC}$ & $292 \mathrm{aC}$ & $427 \mathrm{cC}$ \\
\hline & DG 11002 & $217 \mathrm{bB}$ & $245 \mathrm{bB}$ & $209 \mathrm{bB}$ & $163 \mathrm{aB}$ & $232 \mathrm{~dB}$ \\
\hline & AIXR 11002 & $135 \mathrm{bA}$ & $172 \mathrm{cA}$ & $138 \mathrm{bcA}$ & $105 \mathrm{aA}$ & $139 \mathrm{bcA}$ \\
\hline & $\begin{array}{l}\text { Averages followed by } \\
\text { across distances. }\end{array}$ & lower ca & and upper c & lumn, do no & ng Tukey's tes & 5. Data combined \\
\hline$[\mathrm{b}]$ & $\begin{array}{l}\text { Original data: } \mathrm{F}_{\text {Levene }} \\
8.1^{* *} ; \mathrm{F}_{\text {noz } \times \text { dist }}=89 . \\
\mathrm{F}_{\text {sol } \times \text { noz }}, \mathrm{F}_{\text {sol } \times \text { dist }}, \mathrm{F}_{\text {noz }} \\
\text { nozzle and distance, } 1\end{array}$ & $\begin{array}{l}=0.152 * * \\
\text { olmogor } \\
\text { F-value } \mathrm{f} \\
\text { ignifican }\end{array}$ & $\begin{array}{l}\text { data: } F_{\text {Leven }} \\
(\mathrm{K}-\mathrm{S}) \text { test } \mathrm{v} \\
\text { between so } \\
\text { Non-signif }\end{array}$ & $\begin{array}{l}\mathrm{K}-\mathrm{S}=0.102 \\
\mathrm{~F} \text { statistics. } \\
\text { le, and distar }\end{array}$ & $\begin{array}{l}\mathrm{z} \times \text { dist }=0.9^{\mathrm{ns}} \\
\text { formed by squ } \\
\text { on and nozzle }\end{array}$ & $\begin{array}{l}3^{* *} ; \mathrm{F}_{\mathrm{sol} \times \text { dist }}= \\
. \mathrm{F}_{\mathrm{sol} \times \mathrm{noz} \times \text { dist }} \\
\text { ad distance; and }\end{array}$ \\
\hline
\end{tabular}




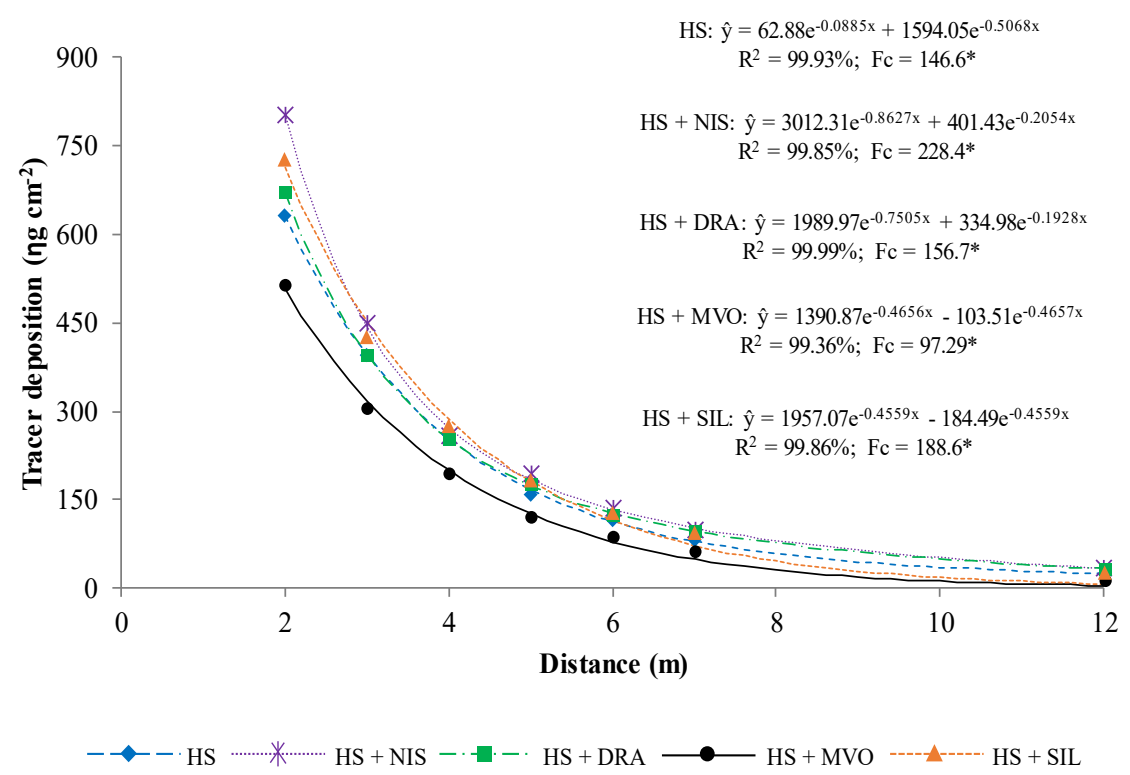

Figure 3. Tracer deposition curves from glyphosate plus 2,4-D amine applications tank-mixed with adjuvants. Data combined across nozzle types. Abbreviations: HS, herbicide solution; NIS, non-ionic surfactant; DRA, drift reduction agent; MVO, modified vegetable oil; SIL, silicone surfactant. Fc, Calculated F-value; *, Significant at $\alpha=0.05$.

coarser and had $2.8 \%$ less fines $\left(\mathrm{V}_{100}\right)$ than the DG nozzle. This illustrates that more factors play a role in spray drift other than droplet size alone. Future research should investigate how droplet velocity, surface tension, and viscosity may affect drift beyond droplet size to more accurately predict drift potential of glyphosate and 2,4-D amine solutions. Droplet size may be a primary factor influencing spray drift; however, Vieira et al. (2020b) reported that droplet velocity and their interactions with droplet size may affect drift potential of pesticide applications. The AIXR nozzle produced the lowest spray depositions at 2.2 and $3.6 \mathrm{~m} \mathrm{~s}^{-1}$ airspeeds (87 and $25 \mathrm{\eta g} \mathrm{cm}^{-2}$, respectively). This indicates that this nozzle is a reliable option in applications of broad spectrum or non-selective herbicides, such as glyphosate and 2,4-D amine, to reduce the potential risk of drift. Since glyphosate and 2,4-D are systemic herbicides, coarser droplets do not necessarily decrease their efficacies (Meyer et al., 2015; Creech et al., 2016), although efficacy is influenced by the interaction between tank-mixture, nozzle, and weed species (Meyer et al., 2015; Butts et al., 2019b). As a result, across treatments evaluated within this research, applications of glyphosate and 2,4-D amine should be made when wind speeds are minimal using an AIXR nozzle and the MVO adjuvant. These application parameters generate a Coarse droplet size, reduce drift potential, and would result in no expected loss in weed control using glyphosate and 2,4-D amine.

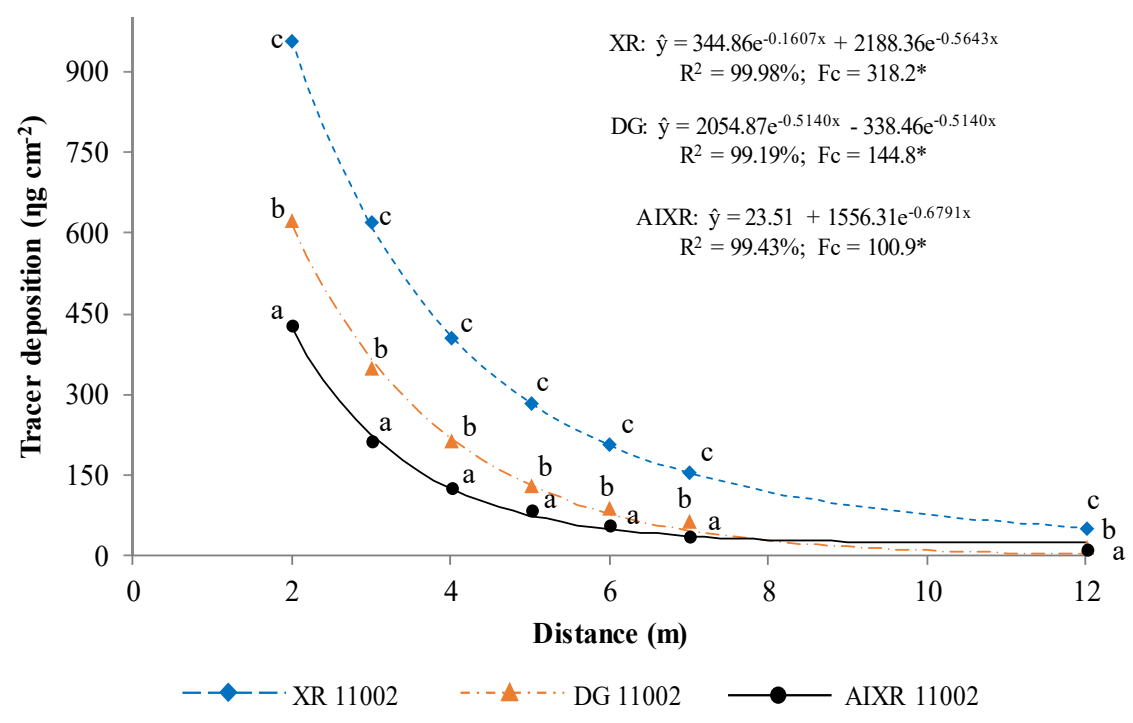

Figure 4. Tracer deposition curves from glyphosate plus 2,4-D amine applications using three nozzle types. Data combined across solutions. Drift values with the same letters between nozzle types within each distance do not differ using Tukey's test at $\alpha=0.05$. Abbreviations: Fc, Calculated F-value; *, Significant at $\alpha=0.05$. 


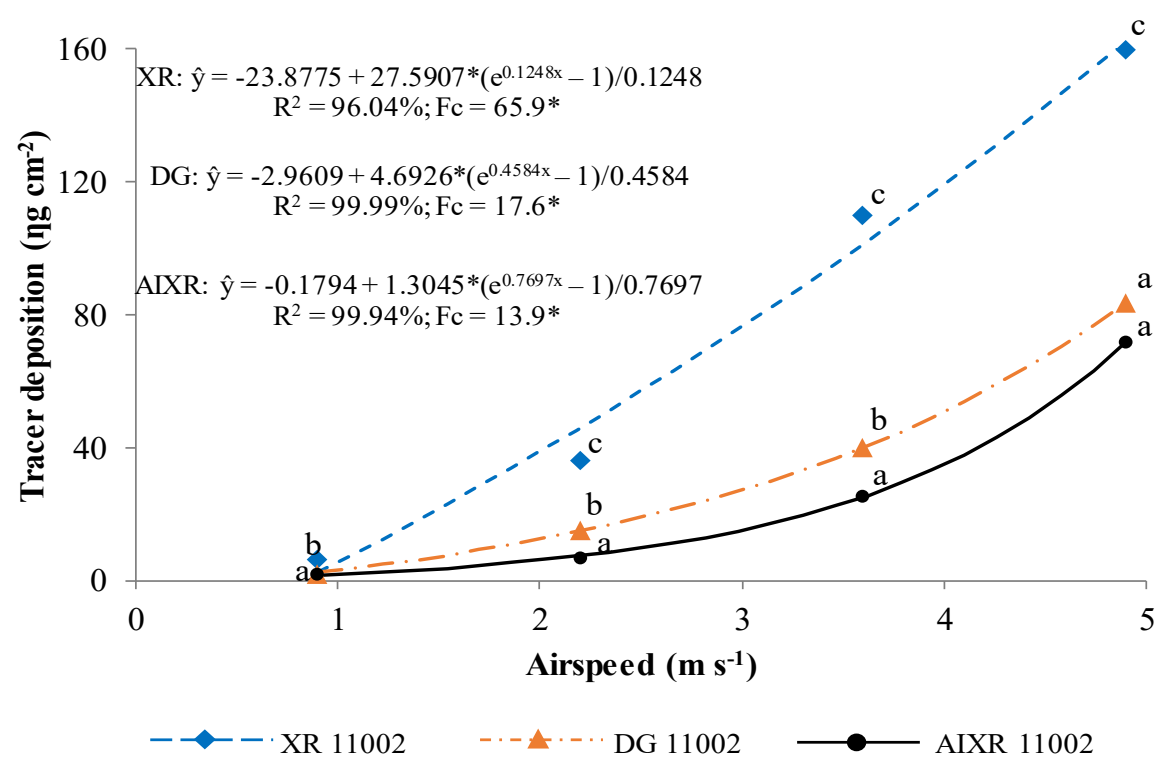

Figure 5. Airspeed effect on tracer deposition at $12 \mathrm{~m}$ downwind in glyphosate plus 2,4-D amine applications using three nozzle types. Drift values with the same letter between nozzle type within airspeed do not differ using Tukey's test at $\alpha=0.05$. Abbreviations: Fc, Calculated F-value; *, Significant at $\alpha=0.05$.

The spray deposition produced through all three nozzles increased non-linearly as the airspeed increased. However, as droplet size decreased (AIXR $>$ DG $>$ XR), the regression of spray deposition had a tendency to become more linear across increasing airspeeds. The function for the XR nozzle had the lowest coefficient of curvature (0.1248). This highlights the complexity of predicting spray drift in real-world field scenarios as the slopes of the models change respective to airspeed and nozzle type interactions. Additionally, as there are many other factors that influence spray drift (Dorr et al., 2013), more research must be conducted on the numerous interactions occurring, like those highlighted in the present research, to effectively predict spray drift.

A study evaluating dicamba spray drift found similar results in terms of modeling drift for the XR and AIXR nozzles (Alves et al., 2017b). Conversely, the authors found that dicamba spray drift increased more linearly when applications were made through an AIXR nozzle compared to an XR nozzle. These results suggest that drift across airspeeds do not solely depend on nozzle type but also on spray solution. More research is needed to fully understand these complex processes before accurate and precise drift estimates can be successfully made with current application technologies.

\section{CONCLUSION}

The AIXR 11002 nozzle produced the coarsest droplets, the lowest percentage of droplets prone to $\operatorname{drift}\left(\mathrm{V}_{100}\right)$, the most homogeneous droplet spectrum (lower RS), and consequently, lowest spray deposition on drift collectors compared to all other treatments evaluated in this research. In applications of the potassium salt of glyphosate (1620 $\mathrm{g}$ ae $\mathrm{ha}^{-1}$ ) plus 2,4-D amine $\left(450 \mathrm{~g}\right.$ ae ha $\left.^{-1}\right)$, the addition of a MVO adjuvant at $2 \% \mathrm{v} \mathrm{v}^{-1}$ increased the droplet size, reduced the drift potential, and produced a more homogeneous droplet spectrum in comparison to the other spray solutions. Conversely, the use of a SIL surfactant reduced the droplet size and increased the potential risk of drift, not only for the AIXR, but also for the DG and XR nozzles. Results suggest that MVO may be used to reduce downwind deposition of glyphosate and 2,4-D amine, whereas SIL, NIS, and DRA adjuvants were unsuccessful at reducing downwind deposition of glyphosate and 2,4-D amine regardless of nozzle type. Spray drift and herbicide efficacy field trials using glyphosate plus 2,4-D amine need to be conducted in order to make a more precise recommendations, especially with the AIXR nozzle and MVO adjuvant.

Spray deposition decreased exponentially as downwind distance increased across herbicide solutions, and increased non-linearly as airspeed increased across nozzle types. Applications of glyphosate and 2,4-D amine during higher airspeeds $\left(5 \mathrm{~m} \mathrm{~s}^{-1}\right)$ should be avoided even when using lowdrift nozzles. Results suggest that pesticide applications at recommended airspeeds combined with nozzle selection should be considered more important factors than adjuvant in order to mitigate spray drift.

\section{ACKNOWLEDGEMENTS}

The authors would like to thank the Coordination for the Improvement of Higher Education Personnel (CAPES-Brazil) for financial support of the first two authors and the research group of the PAT Lab for its assistance, especially the research assistants of 2015 (Luis Tobias, Frederico Guimarães, and Milos Zaric). No conflicts of interest have been declared.

\section{REFERENCES}

Alves, G. S., Kruger, G. R., da Cunha, J. P. A. R., de Santana, D. G., Pinto, L. A., Guimaraes, F., \& Zaric, M. (2017b). Dicamba spray drift as influenced by wind speed and nozzle type. Weed Technol., 31(5), 724-731. https://doi.org/10.1017/wet.2017.61 
Alves, G. S., Kruger, G. R., da Cunha, J. P. A. R., Vieira, B. C., Henry, R. S., Obradovic, A., \& Grujic, M. (2017a). Spray drift from dicamba and glyphosate applications in a wind tunnel. Weed Technol., 31(3), 387-395. https://doi.org/10.1017/wet.2017.15

Anonymous. (2017a). Enlist one specimem label. Retrieved from http://www.cdms.net/ldat/ldE27000.pdf

Anonymous. (2017b). Enlist duo specimem label. Retrieved from http://www.cdms.net/ldat/ldAEA005.pdf

ASABE Standards. (2016). S327.4: Terminology and definitions for applications of crop or forestry production and protective agents. St. Joseph, MI: ASABE.

ASABE Standards. (2017). S572.1: Spray nozzle classification by droplet spectra. St. Joseph, MI: ASABE.

Bish, M. D., \& Bradley, K. W. (2017). Survey of Missouri pesticide applicator practices, knowledge, and perceptions. Weed Technol., 31(2), 165-177. https://doi.org/10.1017/wet.2016.27

Bouse, L. F. (1994). Effect of nozzle type and operation on spray droplet size. Trans. ASAE, 37(5), 1389-1400. https://doi.org/10.13031/2013.28219

Bueno, M. R., da Cunha, J. P. A. R., \& de Santana, D. G. (2017). Assessment of spray drift from pesticide applications in soybean crops. Biosyst. Eng., 154, 35-45.

https://doi.org/10.1016/j.biosystemseng.2016.10.017

Butler Ellis, M. C., \& Tuck, C. R. (2000). The variation in characteristics of air-included sprays with adjuvants. Aspects Appl. Biol.(57), 155-162.

Butler Ellis, M. C., Tuck, C. R., \& Miller, P. C. (1997). The effect of some adjuvants on sprays produced by agricultural flat fan nozzles. Crop Prot., 16(1), 41-50. https://doi.org/10.1016/S0261-2194(96)00065-8

Butts, T. R., Butts, L. E., Luck, J. D., Fritz, B. K., Hoffmann, W. C., \& Kruger, G. R. (2019a). Droplet size and nozzle tip pressure from a pulse-width modulation sprayer. Biosyst. Eng., 178, 5269. https://doi.org/10.1016/j.biosystemseng.2018.11.004

Butts, T. R., Samples, C. A., Franca, L. X., Dodds, D. M., Reynolds, D. B., Adams, J. W.,... Kruger, G. R. (2018). Spray droplet size and carrier volume effect on dicamba and glufosinate efficacy. Pest Manag. Sci., 74(9), 2020-2029. https://doi.org/10.1002/ps.4913

Butts, T. R., Samples, C. A., Franca, L. X., Dodds, D. M., Reynolds, D. B., Adams, J. W.,... Kruger, G. R. (2019b). Optimum droplet size using a pulse-width modulation sprayer for applications of 2,4-D choline plus glyphosate. Agron. J., 111(3), 1425-1432. https://doi.org/10.2134/agronj2018.07.0463

Byass, J. B., \& Lake, J. R. (1977). Spray drift from a tractorpowered field sprayer. Pesticide Sci., 8(2), 117-126. https://doi.org/10.1002/ps.2780080202

Creech, C. F., Henry, R. S., Fritz, B. K., \& Kruger, G. R. (2015). Influence of herbicide active ingredient, nozzle type, orifice size, spray pressure, and carrier volume rate on spray droplet size characteristics. Weed Technol., 29(2), 298-310. https://doi.org/10.1614/WT-D-14-00049.1

Creech, C. F., Henry, R. S., Hewitt, A. J., \& Kruger, G. R. (2018). Herbicide spray penetration into corn and soybean canopies using air-induction nozzles and a drift control adjuvant. Weed Technol., 32(1), 72-79. https://doi.org/10.1017/wet.2017.84

Creech, C. F., Moraes, J. G., Henry, R. S., Luck, J. D., \& Kruger, G. R. (2016). The impact of spray droplet size on the efficacy of 2,4-D, atrazine, chlorimuron-methyl, dicamba, glufosinate, and saflufenacil. Weed Technol., 30(2), 573-586. https://doi.org/10.1614/WT-D-15-00034.1

Derksen, R. C., Ozkan, H. E., Fox, R. D., \& Brazee, R. D. (1999). Droplet spectra and wind tunnel evaluation of venturi and preorifice nozzles. Trans. ASAE, 42(6), 1573-1580.

https://doi.org/10.13031/2013.13322
Dorr, G. J., Hewitt, A. J., Adkins, S. W., Hanan, J., Zhang, H., \& Noller, B. (2013). A comparison of initial spray characteristics produced by agricultural nozzles. Crop Prot., 53, 109-117. https://doi.org/10.1016/j.cropro.2013.06.017

Ebert, T. A., Taylor, R. A. J., Downer, R. A., \& Hall, F. R. (1999). Deposit structure and efficacy of pesticide application. 1: Interactions between deposit size, toxicant concentration and deposit number. Pesticide Sci., 55(8), 783-792.

https://doi.org/10.1002/(sici)1096-9063(199908)55:8<783::aidps973>3.0.co;2-d

Egan, J. F., Barlow, K. M., \& Mortensen, D. A. (2014). A metaanalysis on the effects of 2,4-D and dicamba drift on soybean and cotton. Weed Sci., 62(1), 193-206. https://doi.org/10.1614/WS-D-13-00025.1

EPA. (2017). Models for pesticide risk assessment. Washington, DC. Retrieved from https://www.epa.gov/pesticide-science-andassessing-pesticide-risks/models-pesticide-risk-assessment

Fernandez-Cornejo, J., Nehring, R. F., Osteen, C., Wechsler, S., Martin, A., \& Vialou, A. (2014). Pesticide use in U.S. agriculture: 21 selected crops, 1960-2008. https://doi.org/10.2139/ssrn.2502986

Ferreira, D. F. (2011). A computer statistical analysis system. Cienci. Agrotec., 35(6), 1039-1042. https://doi.org/10.1590/S1413-70542011000600001

Fritz, B. K., Hoffmann, W. C., Bagley, W. E., Kruger, G. R., Czaczyk, Z., \& Henry, R. S. (2014a). Measuring droplet size of agricultural spray nozzles-measurement distance and airspeed effects. Atomization Sprays, 24(9), 747-760. https://doi.org/10.1615/AtomizSpr.2014008424

Fritz, B. K., Hoffmann, W. C., Kruger, G. R., Henry, R. S., Hewitt, A., \& Czaczyk, Z. (2014b). Comparison of drop size data from ground and aerial application nozzles at three testing laboratories. Atomization Sprays, 24(2), 181-192.. https://doi.org/10.1615/AtomizSpr.2013009668

Fritz, B. B., Hoffmann, W. C., \& Jank, P. (2011). A fluorescent tracer method for evaluating spray transport and fate of field and laboratory spray applications. J. ASTM Int., 8(3), 1-9. https://doi.org/10.1520/JAI103619

Gil, E., Balsari, P., Gallart, M., Llorens, J., Marucco, P., Andersen, P. G.,... Llop, J. (2014). Determination of drift potential of different flat fan nozzles on a boom sprayer using a test bench. Crop Prot., 56, 58-68. https://doi.org/10.1016/j.cropro.2013.10.018

Henry, R. S., Fritz, B. K., Hoffmann, W. C., \& Kruger, G. R. (2016). The influence of nozzle type, operating pressure, and tank-mixture components on droplet characteristics and the EPA's drift reduction rating. In C. Poffenberger, \& J. Heuser (Eds.), Pesticide formulation and delivery systems (1st ed., Vol. 36, pp. 149-161). West Conshohoken, PA: ASTM Int. https://doi.org/10.1520/STP159520150098

Hobson, P. A., Miller, P. C. H., Walklate, P. J., Tuck, C. R., \& Western, N. M. (1993). Spray drift from hydraulic spray nozzles: The use of a computer simulation model to examine factors influencing drift. J. Agric. Eng. Res., 54(4), 293-305. https://doi.org/10.1006/jaer.1993.1022

Hoffmann, W. C., Fritz, B. K., \& Ledebuhr, M. (2014). Evaluation of 1, 3, 6, 8-pyrene tetra sulfonic acid tetra sodium salt (PTSA) as an agricultural spray tracer dye. Appl. Eng. Agric., 30(1), 2528. https://doi.org/10.13031/aea.30.10313

Johnson, A. K., Roeth, F. W., Martin, A. R., \& Klein, R. N. (2006). Glyphosate spray drift management with drift-reducing nozzles and adjuvants. Weed Technol., 20(4), 893-897.

https://doi.org/10.1614/WT-05-162.1 
Kalsing, A., Rossi, C. V. S., Lucio, F. R., Zobiole, L. H. S., da Cunha, L. C., \& Minozzi, G. B. (2018). Effect of formulations and spray nozzles on 2,4-D spray drift under field conditions. Weed Technol., 32(4), 379-384. https://doi.org/10.1017/wet.2018.18

Klein, R. N., \& Kruger, G. R. (2011). Nozzles - Selection and sizing. Retrieved from http://extensionpublications.unl.edu/assets/pdf/ec141.pdf

Kudsk, P. (2017). Optimising herbicide performance. In P. E. Hatcher, \& R. J. Froud-Williams (Eds.), Weed research: Expanding horizons (1st ed., Vol. 1, pp. 149-179). Hoboken, NJ: John Wiley \& Sons. https://doi.org/10.1002/9781119380702.ch6

Meyer, C. J., Norsworthy, J. K., Kruger, G. R., \& Barber, T. (2015). Influence of droplet size on efficacy of the formulated products Engenia $^{\mathrm{TM}}$, Roundup PowerMax ${ }^{\circledR}$, and Liberty ${ }^{\circledR}$. Weed Technol., 29(4), 641-652. https://doi.org/10.1614/WT-D-15-00044.1

Miller, P. C. H., \& Butler Ellis, M. C. (2000). Effects of formulation on spray nozzle performance for applications from ground-based boom sprayers. Crop Prot., 19(8), 609-615. https://doi.org/10.1016/S0261-2194(00)00080-6

Miller, P. C. H., \& Hadfield, D. J. (1989). A simulation model of the spray drift from hydraulic nozzles. J. Agric. Eng. Res., 42(2), 135-147. https://doi.org/10.1016/0021-8634(89)90046-2

Mota, A. A. B., \& Antuniassi, U. R. (2013). Influencia de adjuvantes no espectro de gotas de ponta com inducao de ar. Energia Agric., 28(1), 1-5. https://doi.org/10.17224/EnergAgric.2013v28n1p01-05

Neve, P., \& Powles, S. B. (2005). High survival frequencies at low herbicide use rates in populations of Lolium rigidum result in rapid evolution of herbicide resistance. Heredity, 95(6), 485492. https://doi.org/10.1038/sj.hdy.6800751

Nuyttens, D., Baetens, K., De Schampheleire, M., \& Sonck, B. (2007a). Effect of nozzle type, size and pressure on spray droplet characteristics. Biosyst. Eng., 97(3), 333-345. https://doi.org/10.1016/j.biosystemseng.2007.03.001

Nuyttens, D., De Schampheleire, M., Baetens, K., \& Sonck, B. (2007b). The influence of operator-controlled variables on spray drift from field crop sprayers. Trans. ASABE, 50(4), 1129-1140. https://doi.org/10.13031/2013.23622

Oliveira, R. B., Antuniassi, U. R., Mota, A. A. B., \& Chechetto, R. G. (2013). Potential of adjuvants to reduce drift in agricultural spraying. Engenharia Agricola, 33(5), 986-992. https://doi.org/10.1590/S0100-69162013000500010

Parkin, C. S., \& Wheeler, P. N. (1996). Influence of spray induced vortices on the movement of drops in wind tunnels. J. Agric. Eng. Res., 63(1), 35-44. https://doi.org/10.1006/jaer.1996.0005

Reddy, K. N. (2001). Glyphosate-resistant soybean as a weed management tool: Opportunities and challenges. Weed Biol. Manag., 1(4), 193-202. https://doi.org/10.1046/j.14456664.2001.00032.x

Roten, R. L., Ferguson, J. C., \& Hewitt, A. J. (2014). Drift reducing potential of low drift nozzles with the use of sprayhoods. New Zealand Plant Protection, 67, 274-277. https://doi.org/10.30843/nzpp.2014.67.5725
Sidahmed, M. M., Awadalla, H. H., \& Haidar, M. A. (2004). Symmetrical multi-foil shields for reducing spray drift. Biosyst. Eng., 88(3), 305-312.

https://doi.org/10.1016/j.biosystemseng.2004.04.006

Smith, D. B., Bode, L. E., \& Gerard, P. D. (2000). Predicting ground boom spray drift. Trans. ASAE, 43(3), 547-553. https://doi.org/10.13031/2013.2734

Soltani, N., Dille, J. A., Burke, I. C., Everman, W. J., VanGessel, M. J., Davis, V. M., \& Sikkema, P. H. (2017). Perspectives on potential soybean yield losses from weeds in North America. Weed Technol., 31(1), 148-154. https://doi.org/10.1017/wet.2016.2

Soltani, N., Dille, J. A., Burke, I. C., Everman, W. J., VanGessel, M. J., Davis, V. M., \& Sikkema, P. H. (2016). Potential corn yield losses from weeds in North America. Weed Technol., 30(4), 979-984. https://doi.org/10.1614/WT-D-16-00046.1

USDA-NASS. (2017). Agricultural chemical use survey, 2017. Washington, DC: USDA-NASS. Retrieved from https://www.nass.usda.gov/Surveys/Guide_to_NASS_Surveys/ Chemical_Use/index.php

Vieira, B. C., Butts, T. R., Rodrigues, A. O., Golus, J. A., Schroeder, K., \& Kruger, G. R. (2018). Spray particle drift mitigation using field corn (Zea mays L.) as a drift barrier. Pest Manag. Sci., 74(9), 2038-2046. https://doi.org/10.1002/ps.5041

Vieira, B. C., Butts, T. R., Rodrigues, A. O., Schleier, J. J., Fritz, B. K., \& Kruger, G. R. (2020b). Particle drift potential of glyphosate plus 2,4-D choline pre-mixture formulation in a lowspeed wind tunnel. Weed Technol., 34(1), 1-30. https://doi.org/10.1017/wet.2020.15

Vieira, B. C., Luck, J. D., Amundsen, K. L., Gaines, T. A., Werle, R., \& Kruger, G. R. (2019). Response of Amaranthus spp. following exposure to sublethal herbicide rates via spray particle drift. PLoS One, 14(7), 1-19. https://doi.org/10.1371/journal.pone.0220014

Vieira, B. C., Luck, J. D., Amundsen, K. L., Werle, R., Gaines, T. A., \& Kruger, G. R. (2020a). Herbicide drift exposure leads to reduced herbicide sensitivity in Amaranthus spp. Sci. Rep., 10(2046), 1-11. https://doi.org/10.1038/s41598-020-59126-9

Wang, M., \& Rautmann, D. (2009). A simple probabilistic estimation of spray drift-factors determining spray drift and development of a model. Environ. Toxicol. Chem.: An Int. J., 27(12), 2617-2626. https://doi.org/10.1897/08-109.1

Wright, T. R., Shan, G., Walsh, T. A., Lira, J. M., Cui, C., Song, P.,... Zhang, Z. (2010). Robust crop resistance to broadleaf and grass herbicides provided by aryloxyalkanoate dioxygenase transgenes. Proc. Natl. Academy Sci., 107(47), 20240-20245. https://doi.org/10.1073/pnas. 1013154107

Zhu, H., Reichard, D. L., Fox, R. D., Brazee, R. D., \& Ozkan, H. E. (1994). Simulation of drift of discrete sizes of water droplets from field sprayers. Trans. ASAE, 37(5), 1401-1407. https://doi.org/10.13031/2013.28220 